\title{
The decision-making process for breast reconstruction after cancer surgery: representations of heterosexual couples in longstanding relationships
}

Léonor Fasse ${ }^{1}$, Cécile Flahault ${ }^{2}$, Christel Vioulac ${ }^{2}$, Kristopher Lamore ${ }^{2}$, Anna van Wersch ${ }^{3}$, Bruno Quintard ${ }^{4}$, Aurélie Untas ${ }^{2}$,

${ }^{1}$ Université de Bourgogne Franche-Comté, Laboratoire de Psychopathologie et Psychologie Médicale EA 4452, Pôle AAFE. Dijon, France - Hôpital Gustave Roussy, Villejuif, France.

${ }^{2}$ Université Paris Descartes, LPPS EA 4057, IUPDP, Paris, France.

${ }^{3}$ Teesside University, School of Social Sciences \& Law, Social Futures Institute, Middlesbrough, TS1 3BA United Kingdom.

${ }^{4}$ Université de Bordeaux, INSERM U1219 'Bordeaux Population Health Research Center' Team "Psycho-epidemiology of Aging \& Chronic Diseases", Bordeaux, France.

\begin{abstract}
Objectives: Most people deal with intrusive life events such as cancer and the care trajectory together with their intimate partners. To our knowledge, no research has studied the involvement of the partner in the decision-making process facing breast reconstruction (BR) after cancer. This study aims to gain a better understanding of the couples' decision-making process for BR in the cancer context and particularly to investigate the partners' involvement in this process. Method: Eighteen participants (nine women who underwent a mastectomy following a first breast cancer and their intimate partners) took part.. We conducted semidirective interviews and a general inductive approach was chosen to capture the representations of the couples. Results: The women in the sample were aged between 33 and 66 years $(M=54, S D=7.5)$, and their partner between 40 and 76 years $(M=59, S D=11.6)$. The duration of their intimate relationship was on average 18 years $(S D=10.4$; Minimum=4; Maximum=33). The analysis revealed 11 major themes. The 2 most salient ones were "external influence" and "implication of the partner". The exploration of the subthemes revealed that the decision-making process is often reported as an interrelated experience by the couples and as a dyadic stressor. The partner's role is depicted as consultative and mostly supportive. Conclusion: These results provide new insights on the involvement of the partner in decision-making. It is crucial to develop a prospective study, which will facilitate understanding the progression of the decision-making process over time.
\end{abstract}

Key words: cancer; oncology; decision-making process; reconstruction; couples. 


\section{Statement of contribution}

\section{What is already known on this subject?}

Most people deal with intrusive life events such as cancer and the care trajectory together with their intimate partners. Shared decision-making between patients and physicians is now the "Gold Standard" in Western Europe and the US. However, in the context of breast reconstruction (BR) after cancer, factors guiding the decision-making process for BR, especially the potential involvement of the partner, are not very well understood.

\section{What does this study add?}

- Provides a qualitative insight on the specific nature of heterosexual couples 'representations regarding the decision-making process for breast reconstruction after cancer.

- Reveals that the decision-making process is often reported as an interrelated experience by the couples and as a dyadic stressor.

- Underlines the consultative function of partners with women engaged in breast reconstruction.

\section{INTRODUCTION}

Recent statistics suggest that breast cancer is the most common cancer in women worldwide, with the highest incidence rates in Western Europe and the USA (GLOBOCAN 2012). This disease affects one in eight women in the United States, in the UK and France (American Cancer Society, 2016; Cancer Research UK, 2012). One third of breast cancer patients requires a mastectomy, with the option of immediate (IBR) (with mastectomy surgery) or delayed breast reconstruction (DBR) (at least 6-12 months post-mastectomy). Although current guidelines from dedicated medical authorities stress that all women diagnosed with breast cancer who undergo mastectomy have to be offered immediate or delayed breast reconstruction (BR), this procedure remains hardly systematically implemented in Europe and in the US (INCA, 2009; NABON, 2012; NCI, 2012; NICE, 2012). According to Brennan and Spillane (2013) only $16.9 \%$ of women underwent immediate or delayed reconstruction. This result suggests that reconstruction appears to be presented to a minority of women of whom around half takes up the offer.

Shared decision-making between patients and physicians is now the "Gold Standard" in Western Europe and the US (Schifrin, 2001). In the context of breast cancer, it means that any treatment decision, including the reconstruction procedure, is supposed to be discussed to 
ensure that the patient has every available information regarding the procedure and consents to the decision in an informed way (Charles, Gafni, \& Whelan, 2004). However, UK studies showed that the decisions are mostly left to surgeons, based on medical contra-indications (Caldon, Collins, Reed et al., 2011; Mendick, Young, Holcombe \& Salmon, 2010). According to Alderman et al. (2008), only 33\% of patients had a general surgeon discussing BR with them. On the one hand research indicated that women' decisions regarding BR/no BR were influenced by aesthetic/functional reasons (to regain breast shape, to make chest look balanced) and by emotional/psychological reasons (to improve body image and self-esteem) (Flitkroft et al., 2016). On the other hand, the majority of literature highlighted the factors that influence the surgeon decision. The main reasons for reconstruction as reported by surgeons included patient- and adjuvant therapy-related factors: young age (Alderman, 2003; Connors et al., 2016; Platt et al., 2011) white ethnicity (Alderman et al., 2009; Connors et al., 2016; Kruper et al., 2011), private insurance, higher education/income (Platt et al., 2011), early stage, no adjuvant therapy (Brennan \& Spillane, 2013; Greenberg, Weeks \& Stain, 2008).

These statements neglected the emotional upheaval induced by the diagnostic announcement, as well as the treatment plan. Consistent findings showed high psychological morbidity from detection, diagnosis and treatments to follow-up for most women with breast cancer (Brocken, Prins, Dekhuizen, \& van der Heijden, 2012; Swainston, Campbell, van Wersch \& Durning 2012). Recent data on stress and coping in illness have acknowledged that most individuals deal with intrusive life events such as cancer together with their intimate partners (Giannousi, Karademas, \& Dimitraki, 2015; Lim, Shon, Paek, \& Daly, 2014). Models of dyadic or couples' coping (e.g. Berg \& Upchurch, 2007; Bodenmann, 2005) view illness and treatments as frequently shared with the partner. Decisions regarding BR not only affect the female patient, but also the intimate partner. Indeed, the BR (and the absence of reconstruction) will influence the couples' intimacy, and sexual functioning (Charles, Gafni, \& Whelan, 2004; Manganiello, Hoga, Reberte, Miranda, \& Rocha, 2010). Couples not only share thoughts and feelings, they also collaborate and focus on joint problem-solving (Berg \& Upchurch, 2007; Revenson \& DeLongis, 2011; Untas et al., 2009). Götze et al. (2016) recently highlighted that couples coping with cancer tend to react as an emotional system rather than as individuals. This interactive process has been studied in different types of cancer; including colorectal (Dagan et al., 2011; Hagedoorn, Dagan et al., 2011; Traa et al., 2016), prostate (Berg, Wiebe, Bloor, Butner, Bradstreet, Upchurch, et al. 2008; Schum, Skea, McKee, \& N'Dow, 2010; Song, Rini, Ellis, \& Northouse, 2016), head and neck (Badr et al., 2016) and breast (Drabe et al., 2013; Manne, Ostroff, Norton, Fox, Goldstein, \& Grana, 2006; Rottman et al., 2015). In the field of breast cancer, three studies indicated that being in a relationship influenced the decision-making process (Flitkrof et al., 2016; Fobair et al., 2006; Rowland et al., 2000). Recently, Flitcroft et al. (2016) demonstrated that women living with a partner were more likely to choose immediate breast reconstruction rather than delayed reconstruction. However, these results did not take the decision process into account that takes place between the woman and her partner. While recent clinical guidelines highlighted the importance of providing patient-tailored information and encouragement for patients and relatives involvement in the decision-making process, empirical data are lacking on what guides the medical procedure of two partners in a couple. An innovative feature of the 
present study is to examine the representations of both women and their partners confronted by the decision of BR.

To gain a better understanding of the couples' decision-making process for BR in the cancer context, we conducted semi-directive interviews with 9 couples evenly divided over 3 conditions: no-reconstruction (NR), immediate breast reconstruction (IBR) and delayed breast reconstruction (DBR).

\section{METHOD}

\section{Participants}

Eighteen participants ( 9 women who underwent a mastectomy and their intimate partners) took part in this study. The time of the breast cancer diagnosis varied between 2 and 8 years $(\mathrm{M}=5 ; S D=2.4)$. Inclusion criteria were: at least 18 years old, speaking and reading French fluently, being married and/or living together in a heterosexual long-term relationship at least since the breast cancer diagnosis. For women with DBR, BR had to be finished for at least 6 months. Exclusion criteria were: couples where the women had a double mastectomy, presence of learning disabilities or mental disorders, partner having a significant health problem. Homosexual couples were not included, due to gender differences in appraisal and coping, and the prospective of recruiting only a small sample. One couple was recruited in the Bergonie Institute, a French cancer care center in Bordeaux. The other 8 couples (16 participants) were recruited via a community research tool: the Seintinelles platform ${ }^{1}$.

\section{Procedure}

This qualitative study was part of a larger research dedicated to the evaluation of the decision-making process for dyadic coping and BR in 70 women, among whom 42 with their partner (Lamore, Quintard, Flahault, van Wersch \& Untas, 2016). The first nine couples (3 per condition NR/IBR/DBR) who agreed to also participate in the qualitative part were then recruited.

The main aim of this qualitative study was to capture the representations of the decision-making process for BR of the two partners when being interviewed together. During the interviews the following domains were explored: decision about BR and its potential evolution over time, motivations for decision, individual representations of $\mathrm{BR} /$ no $\mathrm{BR}$, beliefs and expectations of the surgical procedure. An interview guide was used, but both women and men were asked to express themselves freely and to follow any associations that emerged. Interviews were conducted by two psychologists (including author LF) specialised in the care of people with cancer as well as research dedicated to couples and family. Interviews were audio recorded with participants' consent and transcribed verbatim.

This study was carried out according to the ethical guidelines of the relevant professional organisations: the APA Ethics Code (American Psychological Association,

\footnotetext{
${ }^{1}$ This platform is very similar to the Army of Women Program in the USA, which promotes the participation of women in any of the breast cancer research studies conducted in a country.
} 
2002), and was approved by the French dedicated institutions (CERES, No. 2014/18, CCTIRS, No. 14.686, CNIL, No. 1836324).

\section{Data Analysis}

A general inductive approach was chosen to capture the representations of the couples (Thomas, 2006). The transcripts were analysed following the recommendations of Thomas regarding inductive coding: preparation of raw data files; close reading of text; creation of categories or themes; overlapping coded and uncoded text; continuing revision and refinement of category system. A theme was defined as a subject or motif when sufficiently characterised as having a broad-based and significant meaning in a person's discourse .

To gain validated and rigorous data, all the steps of the analysis were discussed in a scientific team. After repeatedly and scrupulously reading the transcripts of all interviews, 3 investigators (LF, CV and KL) built and tested a coding framework which was discussed and validated by all authors. The transcripts were then subjected to the QDA Miner 4 software (Provalis Research). A first blind coding session allowed to refine some redundant themes, and to improve the inter-coder agreement. After discussions and a modification of the coding schedule, a second analysis resulted in a free marginal score of .707. This indicated a good inter-coder agreement. The final analysis of data was conducted by the scientific team of authors.

In total, 11 main themes were revealed (see Table 1). For the present paper however, we did not have the space to present all of these and made the decision to focus on the 2 most salient ones (1: 'External influence' and 2 'Implication of the partner' in Table 1). These two themes were selected specifically because of their prevalence in the transcripts (they were present in all interviews and were extensively developed by the participants), and because of the critical insight they had provided towards our research question on what guides the decision of BR or no BR.

[Insert here Table 1]

\section{RESULTS}

The women of the sample were aged between 33 to 66 years $(M=54, S D=7.5)$ and their partner between 40 to 76 years $(M=59, S D=11.6)$. The duration of their intimate relationship was on average 18 years $(S D=10.4$; Minimum $=4$; Maximum=33). The average delay between the diagnosis and the BR (in case of DBR) was 9 months $(S D=10$; Minimum=1; Maximum=27).

Further data analysis of the two main themes revealed several subthemes as displayed in Table 2. In what follows, the results will be presented accordingly. The original French extracts have been translated into English, and original names have been replaced by pseudonyms.

[Insert here Table 2] 


\section{External influence}

The analysis revealed that the decision-making process is mostly driven by an external influence. The choice of BR, or of the absence of reconstruction, did not entirely depend on the wishes and expectations of the woman and her partner. Four subthemes specified this external influence (see Table 2). First, the participants reported that the decision was guided by personalised care (1.1). This subtheme was found by 8 participants. The personalised care based itself on several considerations, focusing on various characteristics of the patient. These were psychological or emotional. For instance, Nathalie, a 51 year old woman, insisted on her emotional vulnerability before the surgery:

And that's why the surgeon understood... very kindly... that I was, psychologically, not able to accept the loss of my breast (...). I was not strong enough to... Then he chose to give me an immediate reconstruction.

Personalised care could also be linked with individual medical and clinical data outcomes. Nicole (aged 59) mentioned these aspects during the interview:

It (the immediate reconstruction) was not even confirmed... It depended on my biopsy during the surgery, and I was told: "well, if the ganglions are not affected, it's ok, otherwise, we will not go forward (with the reconstruction).

We can see that this personalised care, which is a current gold standard in medical care, is an important factor that influences the decision-making process. Besides this factor, the care provision (1.2) itself constituted another external element that strongly guided this process. This second subtheme was revealed by 7 participants. Women reported that the care they were offered seemed to vary with the medical center where they were treated. Nathalie highlighted for instance the elements that critically predetermined her decision:

Er... well... it was a decision... well, actually by default... Er... that is, in the center where I was operated, there was no immediate reconstruction (...). I understood that it could have been different for me... that is, according to the place where I have been treated... Er... that's it, it could have been different. And we (she and her husband) did not ask the question either.

The third subtheme that appeared in the external influence was related to the constraint experience reported by 4 participants. Some women in the study and a few partners argued that the decision-making process was absolutely not a choice, but something which was decided by someone else. Stephanie (aged 54) described this phenomenon several times during the interview:

They (the medical staff) didn't ask us for our opinion... To you (her husband) neither...

Rachel (aged 39) and her husband Ian (aged 40) made a very similar statement:

Ian: But plainly, the reconstruction... that was not presented to us as a choice...

Rachel: No, that's it... it's really a proposition...

Ian: It was a proposition which we should rather respect. 
It is noteworthy that this constraint experience, in the sense of an absence of personal choice, did not necessarily cause distress or upset for the participants. Some of them underlined that in a particularly disturbing context such as the period right after the diagnosis and before the surgery, the patients could not make a decision regarding BR; they felt more comfortable to lean on their physician or surgeon for decision-making. For instance, Catherine's (aged 55) discourse revealed some ambivalence regarding this experience. First, when asked about potential regrets, she stated:

(I could have) asked more questions of the physician... not be passive like I was...

But after this initial statement, she emphasised the difficult burden that defined this period, and talked about the relief that the decision had been taken by someone else:

I had enough pressure with all this history ... I gave myself completely over .

Strikingly, while the majority of participants insisted on the importance of the external influence that guided their decision, they recognised, at the same time that the choice of reconstruction or no reconstruction was their personal and very intimate decision (1.4). This subtheme emerged in 8 interviews. The participants highlighted that the decision-making process was, and could only be, a personal choice, which had not being influenced by relatives. Regarding the question: "did anyone, outside the health professionals, influence this process?", the vast majority of women insisted on the "preserve prevent" aspect of the reconstruction. Robert (aged 67), Stephanie's partner, said:

Er... it's clear that my wife... she does whatever she wants. That's it! That's important. It's her body.

Many times in the interviews, women insisted on this choice, which could be only intimate. "It's my problem (...). It's my life, my body", said Stephanie; Isabelle (aged 49) commented: "And ..we didn't want the decision to be influenced by another person, whatever this decision was". Evelyne (aged 58) shared the same point of view when asked whether other people influenced her choice:

I alone, yes, yes, alone... Yes, yes, nobody influenced me, nobody. They really left me alone. And I found this very good... Nobody told me: « you must do it (the reconstruction) » or "no, you must not do this".

The words of "intimate", "personal", "private" were very frequently associated to the term of "choice" in the interviews. Once again, these were not only the words of the women, but also of their partners.

The analysis of the interviews allowed us to underline the prominence of the major theme "external influence", which indicated the important factors of the decision-making process, that did not belong to the woman or the couple. This influence has been demonstrated by the numerous statements of the participants highlighting the very intimate nature of their choice regarding BR. 


\section{Implication of the partner}

This main theme was spontaneously reported in the 9 interviews. It included 6 subthemes.

First, all the participants insisted on the common experience (2.1) of the care process, shared by both partners. They underlined that the decision-making process itself was a common experience, not an individual one, as noticed by the use of the impersonal pronoun "one" ("on" in French) or by the mention of "we". For instance: "we lived this story...", or " (the surgeon) proposed us a reconstruction », or "we had this (the surgery) in secret". These statements indicated an order of agreement, of the complicity, of the progress in unison. Ian for example, said:

We were in tune during the whole decision-making process.

Some of the partners underlined that they were really involved in this process... as body and soul, as Robert expressed:

Thus here was just the procedure that my wife had to undergo in her body, and that we experienced... I shall say... a little psychologically, both of us ...

This common experience of the care process showed that the couple acted as a unit, experienced as strength for both partners.

Second, 9 women described the very nature of the support provided by their partner as emotional help and reassurance (2.2). This emotional support emerged during the interviews: the partners frequently complimented the women on their courage and expressed their admiration. The husband offered their support to the patients regardless of whether they chose to have a BR or not. Isabelle revealed for instance:

But after he... he played a critical role, because he told me: «you know, if you don't feel like it, if you don't want it, you don't have to do it (the reconstruction). Do as you want, do as you feel."

This unconditional support is reported by the women as very helpful. Their partners were also described as understanding people, attentive to their wives' potential distress. For example, Evelyne said:

He was listening to me... Well he stayed always very calm with all this... Very, very calm... Whatever my temper was, whatever my moods or my doubts were, he was equal... Equal.

As mentioned earlier, the women participating in this study reported painful changes regarding their body image. The emotional support provided by their partners was thus also linked with reassurance of their femininity. Elizabeth (aged 55) told her husband Marc (aged 55) during the interview:

You didn't stop telling me that I was attractive to you, that I am attractive... which finally I believed, you convinced me of it!

The partner, by showing attachment and an even-tempered attitude could in that way participate in the acceptation process. 
Finally, the participants frequently reported that husbands offered practical support (2.3) by: accompaniment during medical appointments, management of everyday life at home, or management of stressful events for their women. For instance, Rachel highlighted:

And he really took care of everything. That is, it's him who booked an appointment at the doctor's, it is him who found the wig... it's true! (she turns to her husband) 'You have made so many things possible'!

This practical support also had an emotional dimension, as described by Evelyne:

He accompanied me at medical appointments, at all appointments ... even the biopsies (...). And the only fact was that you were holding my feet... after the doctor told me "you are really brave ". But my courage was in the hand which was on my foot... there was my courage.

Fourth, for 7 participants, the interviews offered them the opportunity to talk about their intimacy (2.4). The surgery process and the choice of BR deeply marked their life as a couple and especially regarding their intimacy and sexual life. The majority of couples highlighted that their intimate relationship was at first disturbed, for instance because of the impact on body image. As Isabelle and her husband Jacques (aged 51) mentioned:

Isabelle: That is... me... I had to relax on this thing, to allow him touch....

Jacques: Well... You hid a little bit. Isabelle: That's it: I hid a little bit in front of Jacques.

Six women said that their sexual drive was reduced during the treatments and months after. These changes in libido or loss of sex drive were linked with the previously quoted disturbance of body image. While talking about her breast, Stephanie said:

What was an object of pleasure suddenly disappeared (...). It was not a sexual object anymore (...). This part (of my body) is not erotic anymore.

This embarrassment is shared by some partners who feared to hurt their wives with recent surgery stories. Robert explained:

Before that, I felt disturbed, because when I touched her, she had pain.

However, for the participants of our study these troubles affecting their intimacy dissipated gradually over time.

Fifth, 5 participants reported some tensions (2.5) that the couple experienced during the illness and the decision-making process. These tensions or conflicts could derive when the support was perceived as inappropriate by the patient. For instance, Catherine (a retired nurse) highlighted:

Well he (her husband) is so positive that it was a problem for me... For me who was in the (medical) environment, I was afraid... And feeling he was so positive every time, I never could talk about my fears.

Interestingly, Catherine pointed out that a positive attitude, traditionally considered as helpful, could be perceived as a burden when it hinders the communication about negative feelings. This kind of domination of positive thought could thus induce some conflicts in the couple. Some participants reported tensions due to gaps in perceptions, of world representations in the period after treatment. For instance, Ian, Rachel's husband said: 
Hum... I recall the example of the garage door. Hum... well... We had at that time a underground garage...you know, a door to be lowered. And voluntarily... It is true...er... I told her: "well, do it yourself! ". Because it was... it also was my will to tell her: "here we are, you are normal anew... Thus why would I come to help you at this point here? ". That was the object of some tensions between us.

Because he fervently wanted to gain back a kind of normality, Ian required from his wife an identical behaviour to that of before the disease, even if it meant confronting her with her incapacity, and creating tensions.

Sixth, couples mentioned the specific function of the male partner in the decisionmaking process. Seven women indeed highlighted that the partner had a consultative function (2.6) and not a decisive one. This opinion regarding the choice of reconstruction is very important for the women, just as highlighted by Rachel:

No, the only one who... It is your opinion which matters to me (Rachel addresses her husband) ... it is the only one which counts ...

The partner has a very special role in the decision-making-process. He is the one with whom the woman can discuss the consequences of the reconstruction or the absence of a reconstruction. Evelyne for instance mentioned this role of privileged interlocutor endorsed by her husband:

I had asked him the question... I had asked you (to her spouse): would that annoy you to live with an Amazon till the end of your days (laughs)? And you answered: " you do as you want ".

The women of this study strongly emphasised how important and helpful it was to have the chance to talk and to exchange words on this topic of reconstruction. As mentioned earlier, no one but their partner could endorse that role. Women stressed that the decision-making process was not discussed with close others. The husband was an exception. The helpful dimension of this collaboration appeared in the non-directive nature of the debate: the partner could of course give his opinion, but not force the woman to decide, in one way or another. This point was shared by the husbands themselves, who emphasised their consultative and supportive role, getting away from a role of decision making. Robert mentioned for example:

It is: "do as you want, as you think it, as you can..." and here we are. It is: "I am here next to you, but you do what you want ".

Once again this consultative role was well expressed by the husbands, who claimed this specific function. Both partners mentioned that standing back is not a withdrawal, not a fearful attitude, but on the contrary that it is a helpful one. For instance, Nicole said she perceived the consultative function of her husband as very respectful. If he had tried to decide for or against the reconstruction, she told us: "I would decide for myself: it is just a body".

\section{DISCUSSION}

This study highlighted the disease and the decision-making process as an interrelated experience by couples. The male partners mentioned the cancer experience, the treatments and the process of BR as a stressor that they had to cope with, just as the female participants. 
These findings were consistent with previous results regarding the partners' adjustment to cancer. Kayser, Watson and Andrade (2007) identified two patterns of relational coping in couples confronted with breast cancer. The first pattern, mutual responsiveness, reflected that partners were "in it together"; they defined the disease experience as a dyadic stressor, as a "we-disease" that affected both of them. This pattern was revealed in the present study in several interviews by the frequent use of "we", "our", etc. Interestingly, while describing this interrelated experience of cancer and BR, the partners of the study pointed out distinct roles for each of them. The major contribution of this qualitative research lies in the description of the role of the male partner in the decision-making process, as perceived by both partners. There was a distribution of the functions in the couple: the male partner provided emotional and practical support, as consultant, and the woman was the one who experienced changes in her body and who ultimately decided. Even if the participants emphasised that the men did not take part in the decision, the support and the reassurance offered to the woman concerning her femininity (in particular in the case of no BR) participated indirectly towards the decision. However, the men seemed to have difficulties in recognising this participation. The literature reported that the majority of cancer patients' spouses described themselves as helpless and incompetent (e.g. Bultz et al., 2000; Fergus \& Gray, 2009) and in need for more tailored information regarding their partner's breast cancer (Rowland \& Metcalf, 2014); the discourse of the women in our study highlighted that both emotional and instrumental support were enough if consistent with their needs. This is supported by recent literature that showed the protective effect of the perception of good marital relationship in body image disturbance (Cairo Notari et al., 2016) and that empathy from a partner could moderate the impact of body image changes on depressive symptoms (Fang et al., 2015). The supportive role of the partner could be enhanced through support programs dedicated to the decision-making process surrounding breast reconstruction.

This study also revealed that the prominent factors explaining the decision-making process were largely medical and clinical, when reported by women and their partners. The participants indeed underlined that the possibility of the reconstruction was guided by medical factors such as the size of the tumor, the stage of the disease, or the necessity to undergo chemo/radiotherapy. This result confirmed data from previous studies (Caldon, Collins, Reed et al., 2011) highlighting the weight of these factors before any consideration of a shared decision process. The participants rarely mentioned a collaborative process between them and their care providers, as they would follow the best scientific evidence available, as well as their values and preferences.

For the participants of this study, the possibility of having a reconstruction also depended on the institution where they received their care. The crucial influence of surgeons' opinion (based on medical knowledge) may explain the experience of constraint mentioned by the women in this study. Four participants insisted on the fact that the reconstruction was not a choice - whether it took place or not - it was decided by someone else. Strikingly, this experience was not necessarily distressing. The women of this sample reported that leaning on the medical staff was not always difficult; their experience was much more positive. They insisted on their absence of choice, leaving it to the surgeon. But even for those who mentioned some regrets related to this absence of choice, this feeling was very ambiguous. The evocation of regret was fast counterbalanced by the mention of relief. When each one 
highlighted the importance of the shared decision making, including patients who militate in favour of this process, how can we understand this relief? One hypothesis to account for this phenomenon would be that not all patients wanted to take a medical decision on their own. Or this will of autonomy could fluctuate over time. As Nicolai et al. (2015) recently emphasised, the match between cancer patients' preferred and perceived roles is negatively associated with decision regret. A distressing experience of constraint may emerge when a gap exists between some expectations and need of autonomy in the decision-making process on the one hand, and on the other hand, the passive role during this process. But the opposite could also be distressful for some patients, who need to rely completely on their physician. This statement could guide us toward a nuanced position regarding autonomy. Giving autonomy is not to completely leave the weight of the decision to the patient. This study also revealed that the very intimate nature of the decision regarding BR is not incompatible with the advices of the professionals. These experiences can indeed be part of the intimacy of the couple's relationship.

This study encountered several limitations. The first related to the representative nature of the sample. It consisted of participants who had volunteered to take part in the research. Moreover, these results concerned couples who have good and long standing spousal relationships: not only did their relation "survive" the cancer but they were also able to talk about what they experienced together. This may have coloured certain dimensions of the analysis, especially the considerations regarding the decision-making process as a "we experience". It could be interesting to compare these kinds of couples with "newer" ones. One way to mitigate this limitation could be to conduct the recruitment by other methods than the Seintinelles, because such a platform may attract a certain group of participants. In addition, this sample included only heterosexual and white Caucasian people. According to the French legislation, we cannot conduct comparative studies based on ethnical criteria, but further studies could investigate potential characteristics in representations of the LGBT community, or in people with different ethnical background. Finally, our data may have been influenced by interviewing the partners together, rather than individually. Some people could have censored in front of their partner and the discourse of the participants is inevitably shaped by the context of the interview. The second limitation concerned the retrospective design of the research which could have induced reconstruction bias. A worthwhile direction for future research may be the elaboration of a larger and prospective study which can assess and describe the decision-making process for BR when the couples are confronted with this directly.

Despite these limitations, this study enlightened the decision-making process for BR in long standing and heterosexual couples. The interrater fidelity also guaranteed a critical scientific rigour. The study contributed to clarify the various roles of the patient, her partner and her physician. To our knowledge, this is the first qualitative study, using a scientific approach that highlighted couples' representations, not only focusing on physician-patient relationship. Our results allowed stressing the importance of taking into account the partner as a major actor in the BR decision-making process, as well as during the cancer treatments.

Conflict of interest: none

Support for this study came from the Cancéropôle du Sud-Ouest (Emergence 2014) 


\section{REFERENCES}

1. Alderman, A. K., Hawley, S. T., Janz, N. K., Mujahid, M. S., Morrow, M., Hamilton, A. S., ... \& Katz, S. J. (2009). Racial and ethnic disparities in the use of postmastectomy breast reconstruction: results from a population-based study. Journal of Clinical Oncology, 27(32), 5325-5330.

2. Alderman, A. K., Hawley, S. T., Waljee, J., Mujahid, M., Morrow, M., \& Katz, S. J. (2008). Understanding the impact of breast reconstruction on the surgical decision-making process for breast cancer. Cancer, 112(3), 489-494.

3. Alderman, A. K., McMahon, L., \& Wilkins, E. G. (2003). The national utilization of immediate and early delayed breast reconstruction and the effect of sociodemographic factors. Plastic and Reconstructive Surgery, 111(2), 695-705.

4. American

Cancer

Society

(2016), http://www.cancer.org/acs/groups/content/@,research/documents/document/acspc046381.pdf, retrieved on 26/09/2016

5. American Psychological Association. (2002). APA ethics code: Ethical principles of psychologists and code of conduct. American Psychologist, 57, 1060-1073. Retrieved from http://dx.doi.org/10.1037/0003-066X.57.12.1060.

6. Badr, H., Milbury, K., Majeed, N., Carmack, C. L., Ahmad, Z., \& Gritz, E. R. (2016). Natural Language Use and Couples' Adjustment to Head and Neck Cancer. Health Psychology.

7. Berg, A., \& Upchurch, R. (2007). A developmental-contextual model of couples coping with chronic illness across the adult life span. Psychological Bulletin, 133(6), 920-954.

8. Berg, C. A., Wiebe, D. J., Bloor, L., Butner, J., Bradstreet, C., Upchurch, R., Hayes, J., Stephenson, R., Nail, L., \& Patton, G. (2008). Collaborative coping and daily mood in couples dealing with prostate cancer. Psychology and Aging, 23(3), 505-516.

9. Bodenmann, G. (2005). Dyadic coping and its significance for marital functioning. In T. Revenson, K. Kayser, \& G. Bodenmann (Eds.), Couples coping with stress: 
Emerging perspectives on dyadic coping (p. 33-50). Washington, DC: American Psychological Association.

10. Brennan, M. E., \& Spillane, A. J. (2013). Uptake and predictors of post-mastectomy reconstruction in women with breast malignancy-systematic review. European Journal of Surgical Oncology (EJSO), 39(6), 527-541.

11. Brocken, P., Prins, J.B., Dekhuijzen, P.N., van der Heijden, H.F. (2012). The faster the better?-A systematic review on distress in the diagnostic phase of suspected cancer, and the influence of rapid diagnostic pathways. Psycho-Oncology, 21(1), 1-10.

12. Bultz, B. D., Speca, M., Brasher, P. M., Geggie, P. H., \& Page, S. A. (2000). A randomized controlled trial of a brief psychoeducational support group for partners of early stage breast cancer patients. Psycho-Oncology, 9(4), 303-313.

13. Cairo Notari, S., Notari, L., Favez, N., Delaloye, J. F., \& Ghisletta, P. (2016). The protective effect of a satisfying romantic relationship on women's body image after breast cancer: a longitudinal study. Psycho-Oncology.

14. Caldon, L. J., Collins, K. A., Reed, M. W., Sivell, S., Austoker, J., Clements, A. M., ... \& Elwyn, G. (2011). Clinicians' concerns about decision support interventions for patients facing breast cancer surgery options: understanding the challenge of implementing shared decision-making. Health Expectations, 14(2), 133-146.

15. Cancer Research UK, 2012, http://www.cancerresearchuk.org/our-research-on-breastcancer, retrieved on 29/03/2016.

16. Charles, C., Gafni, A., \& Whelan, T. (2004). Self-reported use of shared decision-making among breast cancer specialists and perceived barriers and facilitators to implementing this approach. Health Expectations, 7(4), 338-348.

17. Connors, S. K., Goodman, M. S., Myckatyn, T., Margenthaler, J., \& Gehlert, S. (2016). Breast reconstruction after mastectomy at a comprehensive cancer center. SpringerPlus, 5(1), 1-9.

18. Dagan, M., Sanderman, R., Schokker, M. C., Wiggers, T., Baas, P. C., van Haastert, M., Hagedoorn, M. (2011). Spousal support and changes in distress over time in couples coping with cancer: The role of personal control. Journal of Family Psychology, 25(2), 310-318. 
19. Drabe, N., Wittmann, L., Zwahlen, D., Büchi, S., \& Jenewein, J. (2013). Changes in close relationships between cancer patients and their partners. Psycho-Oncology, $22(6), 1344-1352$.

20. Fang, S. Y., Chang, H. T., \& Shu, B. C. (2015). The moderating effect of perceived partner empathy on body image and depression among breast cancer survivors. Psycho-Oncology, 24(12), 1815-1822.

21. Fergus, K. D., \& Gray, R. E. (2009). Relationship vulnerabilities during breast cancer: patient and partner perspectives. Psycho-Oncology, 18(12), 1311-1322.

22. Flitcroft, K., Brennan, M., Costa, D., Wong, A., Snook, K., \& Spillane, A. (2016). An evaluation of factors affecting preference for immediate, delayed or no breast reconstruction in women with high-risk breast cancer. Psycho-Oncology.

23. Fobair, P., Stewart, S.L., Chang, S., D’Onofrio, C., Banks, P.J., \& Bloom, J.R. (2006). Body image and sexual problems in young women with breast cancer. PsychoOncology, 15(7), 579-594.

24. Giannousi, Z., Karademas, E. C., \& Dimitraki, G. (2015). Illness representations and psychological adjustment of Greek couples dealing with a recently-diagnosed cancer: dyadic, interaction and perception-dissimilarity effects. Journal of behavioral medicine, 39(1), 1-9.

25. GLOBOCAN, Ferlay, J., Soerjomataram, I., Ervik, M., Dikshit, R., Eser, S., Mathers, C., Rebelo, M., Parkin, D.M., Forman, D., Bray, F. GLOBOCAN 2012 v1.0, Cancer Incidence and Mortality Worldwide: IARC CancerBase No. 11 [Internet]. Lyon, France: International Agency for Research on Cancer; 2013. Available from: http://globocan.iarc.fr, accessed on 29/03/2016.

26. Götze, H., Friedrich, M., Brähler, E., Romer, G., Mehnert, A., \& Ernst, J. (2016). Psychological distress of cancer patients with children under 18 years and their partners - a longitudinal study of family relationships using dyadic data analysis. Supportive Care in Cancer, 1-10. 
27. Greenberg, C. C., Lipsitz, S. R., Hughes, M. E., Edge, S. B., Theriault, R., Wilson, J. L., ... \& Weeks, J. C. (2011). Institutional variation in the surgical treatment of breast cancer: a study of the NCCN. Annals of surgery, 254(2), 339.

28. Greenberg, C. C., Weeks, J. C., \& Stain, S. C. (2008). Disparities in oncologic surgery. World journal of surgery, 32(4), 522-528.

29. Hagedoorn, M. , Dagan, M., Puterman, E., DeLongis, A., Hoff, C., Meijerink, W. J. H. J., \& Sanderman, R. (2011). Marital satisfaction in couples confronted with colorectal cancer: The interplay of past and current spousal support. Journal of Behavioral Medicine, 34(4), 288-297.

30. Institut National du Cancer (2009). Recommandations professionnelles de l'INCA. Cancer $d u$ sein in situ. Retrieved from http://www.e-cancer.fr/publications/55recommandations-de-pratique-clinique/601-cancer-du-sein-in-situ-recommandationsargumentées.

31. Kayser, K., Watson, L. E., \& Andrade, J. T. (2007). Cancer as a" we-disease": Examining the process of coping from a relational perspective. Families, Systems, \& Health, 25(4), 404.

32. Kruper, L., Holt, A., Xu, X. X., Duan, L., Henderson, K., Bernstein, L., \& Ellenhorn, J. (2011). Disparities in reconstruction rates after mastectomy: patterns of care and factors associated with the use of breast reconstruction in Southern California. Annals of Surgical oncology, 18(8), 2158-2165.

33. Lamore K, Quintard B, Flahault, van Wersh A, Untas A. (2016). Evaluation of the impact of breast reconstruction in women in couple through a community-based research tool: the Seintinelles. Bull Cancer, accepted.

34. Lim, J. W., Shon, E. J., Paek, M., \& Daly, B. (2014). The dyadic effects of coping and resilience on psychological distress for cancer survivor couples. Supportive Care in Cancer, 22(12), 3209-3217.

35. Manganiello, A., Hoga, L.A.K., Reberte, L.M., Miranda, C.M. \& Rocha, C.A.M. (2010). Sexuality and quality of life of breast cancer patients post mastectomy. European Journal of Oncology Nursing, 14 (2), 93-102. 
36. Manne, S. L., Ostroff, J. S., Norton, T. R., Fox, K., Goldstein, L., \& Grana, G. (2006). Cancer-related relationship communication in couples coping with early stage breast cancer. Psycho-Oncology, 15(3), 234-247.

37. Mendick, N., Young, B., Holcombe, C., \& Salmon, P. (2010). The ethics of responsibility and ownership in decision-making about treatment for breast cancer: triangulation of consultation with patient and surgeon perspectives. Social science \& medicine, 70(12), 1904-1911.

38. Nationaal Borstkanker Overleg Nederland. NABON (2012). Mammacarcinoom. Landelijke richtlijn, versie: 2.0. Retrieved from http://www.oncoline.nl/mammacarcinoom.

39. National Cancer Institute. NCI (2012). Breast cancer treatment (health professional). Retrieved from:http://www.cancer.gov/cancertopics/pdq/treatment/breast/healthprofessional.

40. National Institute for Clinical Excellence (2012). New NICE guidelines on the treatment and care of people with early breast cancer. Retrieved from http://www.nice.org.uk/media/AE5/5B/2009013EarlyBreastCancer.pdf.

41. Nicolai, J., Buchholz, A., Seefried, N., Reuter, K., Härter, M., Eich, W., \& Bieber, C. (2015). When do cancer patients regret their treatment decision? A path analysis of the influence of clinicians' communication styles and the match of decision-making styles on decision regret. Patient Education and Counseling. Available online (doi:10.1016/j.pec.2015.11.019)

42. Platt, J., Baxter, N., \& Zhong, T. (2011). Breast reconstruction after mastectomy for breast cancer. Canadian Medical Association Journal, 183(18), 2109-2116.

43. Revenson, T. A., \& DeLongis, A. (2011). Couples coping with chronic illness. In S. Folkman (Ed.). The Oxford handbook of stress, health, and coping. New York: Oxford University Press.

44. Rottmann, N., Hansen, D. G., Larsen, P. V., Nicolaisen, A., Flyger, H., Johansen, C., \& Hagedoorn, M. (2015). Dyadic coping within couples dealing with breast cancer: A longitudinal, population-based study. Health Psychology, 34(5), 486.

45. Rowland, J. H., Desmond, K. A., Meyerowitz, B. E., Belin, T. R., Wyatt, G. E., \& Ganz, P. A. (2000). Role of breast reconstructive surgery in physical and emotional 
outcomes among breast cancer survivors. Journal of the National Cancer Institute, 92 (17), 1422-1429.

46. Rowland, E., \& Metcalfe, A. (2014). A systematic review of men's experiences of their partner's mastectomy: coping with altered bodies. Psycho-Oncology, 23(9), 963974.

47. Schifrin, E. (2001). An overview of women's health issues in the United States and United Kingdom. Women's Health Issues, 11(4), 261-281.

48. Schum, K., Skea, Z., McKee, L., \& N'Dow, J. (2010). 'They're doing surgery on two people': a meta-ethnography of the influence on couples' treatment decision-making for prostate cancer. Health expectations, 13(4), 335-349.

49. Song, L., Rini, C., Ellis, K. R., \& Northouse, L. L. (2016). Appraisals, perceived dyadic communication, and quality of life over time among couples coping with prostate cancer. Supportive Care in Cancer, 1-9.

50. Swainston, K., Campbell, C. \& van Wersch, A. (2012). Treatment decision-making in breast cancer: A longitudinal exploration of women's experiences. British Journal of Health Psychology, 17(1), 155-170.

51. Thomas, D. R. (2006). A general inductive approach for analyzing qualitative evaluation data. American journal of evaluation, 27(2), 237-246.

52. Traa, M. J., Vries, J., Roukema, J. A., \& Oudsten, B. L. (2016). The association between patient's and partner's fatigue in couples coping with colorectal cancer: a longitudinal study. Supportive Care in Cancer, 1-9.

53. Untas, A., Quintard, B., Koleck, M., Borteyrou, X., \& Azencot, A. (2009). Impact de la gestion dyadique du stress sur l'ajustement à une reconstruction mammaire différée après cancer. In Annales Médico-psychologiques, revue psychiatrique (Vol. 167, No. 2, pp. 134-141). Elsevier Masson.

Table 1 : The 11 major themes revealed by the analysis 
1/ External influence (in the decision-making process);

2/ Implication of the partner in the decision-making process;

$3 /$ In favor of the reconstruction;

4/ Against the reconstruction;

5/ Regrets/difficult aspects linked with (no)reconstruction;

6/ Temporality (of the decision-making process);

7/ Illness and treatments;

8/ Relationships with the health professionals;

9/ Relationships with others (relatives, family, friends);

10/ Feelings;

11/ Seeking for information. 
Table 2 : The selected 2 major themes with their subthemes

1/ External influence in the decision-making process:

1.1. personalised care

1.2. care provision

1.3. constraint experience

1.4. intimate decision

2/ Implication of the partner in the decision-making process:

2.1. common experience of care process

2.2. emotional help and reassurance

2.3. practical support

2.4 intimacy

2.5. tensions

2.6. consultative function 